*Helen Walkington, Ph.D., NTF, PFHEA

Professor of Higher Education

Oxford Brookes University

Oxford,

Oxfordshire OX3 OBP

UK

+ 00441865483185

hwalkington@brookes.ac.uk

http://orcid.org/0000-0003-2101-472X

${ }^{*}$ Corresponding author

Kearsley A. Stewart, Ph.D.

Professor of the Practice, Global Health and Cultural Anthropology

Duke University

Durham, NC

USA

(919) 681-8811

k.stewart@duke.edu

https://orcid.org/0000-0002-9624-9956

Eric E. Hall, Ph.D.

Professor of Exercise Science

Elon University

Elon

NC 27244

USA

(336) 278-5880

ehall@elon.edu

https://orcid.org/0000-0002-3590-5390

Elizabeth Ackley, Ph.D.

Associate Professor, Health and Human Performance

Roanoke College

Salem, VA 24153, USA

540-375-5292

ackley@roanoke.edu

Jenny Olin Shanahan, Ph.D.

Assistant Provost

Bridgewater State University

Bridgewater

MA 02325

USA

508-531-2764

jshanahan@bridgew.edu 
Salient Practices of Award-Winning Undergraduate Research Mentors - Balancing Freedom and Control to Achieve Excellence.

\begin{abstract}
:
This paper contributes to research on teaching excellence by extending the current body of literature pertaining to mentoring pedagogies in undergraduate research settings across diverse social, institutional and disciplinary contexts. Our data comes from in-depth interviews with 32 international faculty who have received excellence awards for undergraduate research mentoring. The data reveal a freedom - control dialectic, illuminating the ways in which expert mentors negotiate the desire to create opportunities for students to experience freedom and creativity in research, yet maintain control over the topic, quality and outcomes. The research findings reveal a defining characteristic of award-winning mentors as an ability to establish and sustain a sense of challenge, while maintaining meaningful engagement and a sense of achievement amongst students. The findings show the importance of tailoring practice to the needs of particular student groups, and there are implications for institutional resourcing, as well as mentor training and development.
\end{abstract}

\title{
Keywords
}

Undergraduate research, mentoring, teaching excellence, practice theory, high-impact practices. 


\section{Salient Practices of Award-Winning Undergraduate Research Mentors - Balancing Freedom and Control to Achieve Excellence.}

\section{Introduction}

The identification of undergraduate research (UR) as a high-impact educational practice (HIP; Kuh 2008) has added to its growth as an international movement. New national frameworks for Research Excellence and Teaching Excellence around the world have created additional emphasis on enhancing teaching, learning and the student experience through engagement with research. Institutional strategies to support a research-teaching nexus (Fung 2017; Jenkins and Healey 2005) have provided further impetus for pedagogic development to support this work. Furthermore, data suggest that UR offers particular gains for students from underserved populations (e.g. Brownell and Swaner 2010; Finley and McNair 2013), at a time when persistent attainment gaps (Tatlow 2015) have been identified. Understanding high-quality research mentoring, the essential factor that changes a research project into a transformational learning experience, is therefore essential.

The growth of UR has seen four significant changes in the last decade. First, UR has expanded beyond the laboratory sciences, to mathematics, social sciences, arts and humanities, and professional disciplines (Shanahan et al. 2015) and been associated with use of the term "Undergraduate Research, Scholarship, and Creative Activity" (Crawford and Shanahan 2014). Second, the availability of UR opportunities in an array of institution types has increased including, for example, community colleges in the U.S. (Hensel and Cejda 2014) and further-education colleges in the UK (Healey, Jenkins and Lea, 2014). Third, broader UR experiences include not only the one-to-one selective "apprenticeship" model between a student and a faculty member, but also more democratic, embedded coursebased experiences that involve diverse groups of students in scholarly research (Brush et al. 2010; Corwin, Graham, and Dolan 2015). Finally, a growth in commitment to research dissemination, associated with the drive for public accountability and visibility of research through the open access movement, has precipitated high-profile prestigious events such as 'Posters on the Hill' (Capitol Hill in the US) and Posters in Parliament (UK), as well as national and international conferences such as the British Conference of Undergraduate Research (BCUR) in 2010, International Conference of Undergraduate Research (2013) and Australasian Conference of Undergraduate Research (ACUR) (2014). In 2017 the first World Congress on Undergraduate Research (WCUR) was held in Qatar, with the second in Germany in 2019. There has also been a proliferation of dedicated online student research journals taking work into the public domain. 
Of the HIPs identified by the Association of American Colleges \& Universities (AAC\&U), UR has been most significantly correlated with a wide range of learning outcomes, including critical thinking and analysis (Brownell and Swaner 2010; Kilgo, Sheets, and Pascarella 2015; Kuh 2008). Those learning outcomes have been shown to depend on effective mentoring (Shellito et al. 2001; Shore 2005; Thiry and Laursen 2011). . Undergraduate research mentoring can be defined as "a serious, collaborative interaction between the faculty mentor and the student, in which the student is intellectually engaged in the scholarly problem or project. The faculty mentor guides the student into deeper intellectual engagement over the course of their collaboration. The faculty mentor's attention is equally focused on the student's development and on the results or product of the scholarly or creative project" (Osborn and Karukstis, 2009, p. 42). Research studies of studentresearchers' experiences have shown that mentoring is fundamental to the research experience and to students' success. For example, Pita et al (2013) reported among "student-derived insights" into undergraduate research experiences that mentors' availability, community-building, understanding, and attentiveness could ultimately determine the quality of student work (p. 11). A multi-institutional study by Bradley et al (2017) also found that mentors who shared information, feedback, and logistical support were considered most vital to student achievement in research. A recent large-scale study by Johnson and Stage (2018) affirms the need for more research on what makes a program "high-impact," as simply offering what is on the AAC\&U list does not necessarily result in higher graduation rates. AAC\&U researchers themselves have argued that systematic, high-quality implementation is critical to student learning and successful outcomes in practices such as undergraduate research (Kuh and O'Donnell, 2013). Despite multiple accounts of the fundamental role of "effective mentoring" in successful undergraduate research, overarching guidelines on what constitutes quality mentoring do not exist. This study seeks to address the need for evidence-based mentoring practices that differentiate UR as a distinctive HIP.

This paper outlines a summary of salient practices of UR mentors as currently described in the literature (Shanahan et al. 2015), as well as characteristics of high-impact pedagogic practices (Kuh and O'Donnell, 2013), then presents results from 32 in-depth interviews with award-winning UR mentors from four countries about their practice. The paper explores the themes that emerged and demonstrates a freedom and control dialectic, showcasing exemplars from a range of contexts. 


\title{
Theoretical framework
}

Building on the work of early $20^{\text {th }}$-century philosopher Ludwig Wittgenstein, social scientist Peter Winch (1990) suggested that a practice is comprised of rules and codes, tacit or explicit, within which a shared vocabulary is embedded. Practices operate at the level of meaning and are learned, like a language. Therefore, the social context in which practices are performed is important. Another conception of practice, based in Aristotelian thought, is provided by contemporary ethicist Alisdair Macintyre (2007), who defines a practice as more than a socially constructed set of learned rules and codes. Macintyre (2007: 187) advocates understanding a practice in terms of the values it is trying to attain and effect:

\begin{abstract}
[A practice is] any coherent and complex form of socially established cooperative human activity through which goods internal to that form of activity are realized in the course of trying to achieve those standards of excellence which are appropriate to, and partially definitive of, that form of activity, with the result that human powers to achieve excellence, and human conceptions of the ends and goods involved, are systematically extended.
\end{abstract}

Macintyre suggests that a practice has its own underlying values (virtues or dispositions) and its own internal standards of excellence. "Goods" of a practice are its inherent virtues. In terms of the practice of mentoring UR, the "goods" or benefits may include guiding students to understand research in the context of a disciplinary ethical framework, developing persistence as researchers, and inculcating a desire in students to share findings with an appropriate audience. To understand UR mentoring as a practice, we therefore need to know what its standards of excellence are, i.e. what constitutes "excellent" mentorship. In eliciting accounts of effective practice from award-winning mentors, we aim to describe what people do within the social context of their discipline and institution, as well the individual context of their motivations and values as an academic research mentor. With those standards and values taken as a whole, we also attain an understanding of what constitutes mentoring excellence.

Understanding what constitutes excellence in UR programs and other HIPs was also an impetus for Kuh and O'Donnell's (2013) work, which identified eight quality indicators or 'elements' common to high-impact pedagogical work. Their research pinpointed the shared elements of successful programs and curricula, making explicit the characteristics of HIPs which hold particular value for students. For instance, an UR experience does not convey 
benefits by its existence on a campus, but through the long-standing investment of time and effort that the research requires.

Kuh and O'Donnell's (2013) elements of HIPs describe student inputs and program characteristics essential to success, rather than faculty practices. However, effective mentoring can be usefully framed against the eight elements. Mentoring practices, specific to UR, have been described by Shanahan et al. (2015) in a review of the literature on UR mentoring over the last two decades. Ten salient practices associated with effective UR mentoring emerged from over 100 articles representing a range of disciplines and institutional types (Table 1).

\section{*Table 1 near here (appended at end)*}

The aim of this paper is therefore to explore the practices of award-winning UR mentors from around the world framed against the ten salient practices and the characteristics of highimpact pedagogic work. In doing so, we highlight the defining characteristics for this group of academics and draw out underlying values supporting their practice.

\section{Methods}

An international database of award-winning mentors was created to identify and recruit a diverse participant pool who had been recognised for excellence in UR mentoring. To qualify for inclusion, individuals had to be the recipient of a national- or institutional-level award for excellence in mentoring undergraduate research, based upon peer-reviewed selection committees, between the years of 2012 to 2017 . Each type of award had its own criteria and selection process. For example, National Teaching Fellows in England are selected in a robust process of double-blind peer review of evidence-based documentation. Council on Undergraduate Research (CUR) Fellows go through a multi-stage progression of evaluation, beginning with an extensive nomination procedure, followed by requests for further documentation by a Nominations Committee whose sole purpose is evaluating and winnowing the nominees. What the various awards we included share in common is rigorous peer review. We sought "award winners" whose success as mentors of undergraduate research had been evaluated by their institutional, disciplinary, and/or organizational peers. 
Once we had a diverse list of award-winning mentors, web searches were used to collect: name, gender, rank, discipline, and year of award, as well as institutional type and country. The resulting database included 113 potential participants from the US, UK, Canada, and Australia. From this database, the authors identified 61 potential interviewees to ensure a spread of demographic, disciplinary, and locational factors, of whom 32 completed the interviews. Participant characteristics can be seen in Table 2, with disciplinary areas shown in Table 3.

* Table 2 about here (appended at end)*

* Table 3 about here (appended at end)*

Three members of the research team carried out in-depth, 60-75 minute interviews about UR mentoring. The interview guide (see supplementary materials 1 ) explored pathways into UR mentoring, the nature of the mentor-mentee relationship, effective research mentoring practices, challenges to successful mentoring, and the perceived future of UR mentoring. Following transcription, two members of the team independently coded the interviews, using an inductive approach allowing patterns to emerge from the interview data, followed by crosschecking by the remaining three members to ensure optimal inter-rater reliability. The online qualitative software program Dedoose allowed members to access the interviews simultaneously from different locations. Using thematic analysis (Guest, MacQueen and Namey 2012), interpretive analysis focussed on eliciting salient practices described by the award-winning UR mentors.

\section{Results}

\section{Freedom and control dialectic}

At a meta level, a threefold thematic structure of 'creating challenge', 'sustaining engagement' and 'celebrating achievement' emerged from the reported practices. For each of these themes the practice descriptions revealed a productive tension between freedom and control. The three meta-themes are exemplified in turn, exploring the freedom and control dialectic with representative verbatim quotes from award-winning mentors, cross referenced to the quality characteristics of HIPs (Kuh and O'Donnell 2013) and the ten salient practices for UR mentoring (Shanahan et al. 2015). In so doing, award-winning practice is explicitly described eliciting indicators of mentoring excellence and implicit values underlying mentoring practice. 


\section{Theme 1. Creating challenge}

Mentors created challenge through a combination of control over the level of expectations of the UR experience (high expectations) and the creation of a suitable research environment, within which students were expected to respond to the freedom provided within that space to work to their best ability. Each of these themes is exemplified below.

\subsection{High standards}

Insisting on extremely high standards was a prominent feature of award-winning practice. The key difference between the practice identified from the literature (Salient Practice 2: 'Set clear, scaffolded expectations') and the practice reported by award-winning mentors was in the height of expectations. Award-winning mentors balanced very high expectations with a 'safety net' environment to foster student achievement. Salient practice 4 describes 'rigorous expectations' balanced with emotional support. An example of this is engaging students in research at a level which can be published:

I usually find that I am the first person to really hold students accountable for high quality writing, even though they have been through all the writing courses that the university has. I am not really a writing expert but because the barrier for publication is so high this will be the first time someone has [held them to account]. [H2, Male, STEM (Maths/computer science), Institutional award, US]

Holding students accountable for writing to publication standard shows a mentor working in a challenging space, but one that is essential to success, thereby modelling flexibility and risk-taking. Award-winners described how high expectations were coupled with support, and as they had become more experienced mentors, they were more nuanced in their ability to push mentees to their limit. One participant commented 'l've gotten better at being both more demanding and more forgiving at the same time' going on to explain how experience of high standards was intentionally embedded in a programme:

All of the juniors go to the senior project night and watch the seniors present their work and that's always an eye-opening experience for them, they are humbled and terrorized by the experience. They are amazed that their colleagues are able to do the work that they do, and also scared that they are going to have to do the same thing the following year. [K9, Male, Social sciences (Urban planning), Institutional award, US]. 
Communicating clear expectations by holding students to high standards, telling students when they are not meeting those standards and clarifying what students need to do to meet them were frequently mentioned practices. Mentors created individual development plans and contracts with students, clarifying mentor and mentee commitments.

Award-winning mentors intentionally take students to a liminal space (Cook-Sather and Alter 2011) through constantly adjusting the balance between freedom and control, thus allowing students to experience the frustrations of research, but at a controlled level.

I don't do anything for the students that they can do for themselves. I'm really anti, I wouldn't say 'handholding' because I would hold their hands and make tea while they're working through a tough analysis or writing papers that are hard to do. I try as much as I can [to] meet them at the edge of their capacity and pull them toward that edge. [H3, Female, STEM (Neuroscience), Institutional award, US]

Kuh and O'Donnell (2013) describe 'performance expectations set at appropriately high levels' (Element 1) as integral to high-impact pedagogy. The award-winning mentors are defined by this characteristic, challenging students to achieve beyond their perceived capabilities, and it goes hand-in-hand with a significant and sustained investment in time and effort (Element 2) based on long-term mentoring. Mentors described making themselves available (through being present, approachable, meeting regularly, responding quickly), and demonstrating their commitment through developing their practice as mentors by observing other faculty; leveraging resources to support students; mentoring beyond their area of expertise in order to follow student interests; and, in a couple of cases changing university for a position with a focus on UR mentoring.

\subsection{Create the right environment}

Mentors reported creating an environment conducive to student achievement through setting achievable targets and clear research goals to create authentic research opportunities. Balanced with this was the excitement and discovery of 'real' research, sufficiently authentic that failure was a possibility. This practice was enacted by negotiating the research topic, structuring timeframes, and providing a safety net to accommodate novice researcher limitations.

They actually have to do things with their hands, be careful and not drop things, not put the wrong solution in the wrong tube. I think there's 
something added there, which to begin with in a project is fraught in terms of how that might affect their own reflection of their progress. So part of it is getting them to reflect on what they're learning on a day to day basis in developing these technical skills, even if it looks like everything's failing. [H9, Male, STEM (Bioscience), National award, UK]

In the process of 'teaching the technical skills, methods, and techniques of conducting research in the discipline' (Salient Practice 3), mentors created a distinctive environment through the freedom and control dialectic. A significant part of controlling the environment was careful scaffolding. One example of this embodies Salient Practice 7 'Increase student ownership of the research over time'. Ownership of topic choice was practiced by asking questions in a facilitative style, enabling students to articulate their own topic. Negotiating the balance between maintaining control and giving a sense of freedom is demonstrated in the following extracts:

I direct them a lot, but I direct them in ways that empower them to ask questions... they come up with the idea on their own. [J4, Female, STEM (Biology), National award, US]

I lay out what I think are really important problems in the field, then ask what problem are you interested in solving? Together we sit down to try to design some research that tests that problem. And I think the critical feature is that they have ownership of it... they feel like it's their project, but, I've gently swayed them in a particular direction because I'm trying to get a program of research going too. [K3, Male, Social Sciences (Psychology), National Award, US]

Scaffolding was also mentioned in terms of structuring time, as well as reading and writing processes. Mentors created milestones as students lacked experience with time management over long-term project work. In terms of writing:

I have to break down things like 'how do you write an introduction section?' or 'how do you pull together discussion?' The more minute details I get down to with them, the easier it is for me to realise ways to write my own research. [K5, Female, Social Sciences (Psychology), Institutional award, US]

This section has shown how creating challenge is a function of strong mentor control over standards and expectations developed in an environment where students can experience 
the freedom to take ownership of the research. Award-winning mentors maintain a careful balance for their students between the freedom to fail and the freedom to learn. It is important to note that finding the right balance was challenging for mentors. Project development, especially project design e.g. creating projects of the right level for undergraduate students and defining the project goal were highly skilled tasks. Balancing high expectations with a safety net was also a practice that the award winners were continually refining over time as they worked with different students.

\section{Theme 2. Sustaining engagement}

Mentors created the optimum environment for productive and sustained student engagement with research by controlling student participation. Mentors were intentional about involving particular students, and balanced freedom and control by progressively tailoring the experience to individuals, allowing each student researcher opportunities for ongoing, personalized development. Disciplinary differences arose in descriptions of this practice, as laboratory and applied disciplines more commonly reported team-based mentoring approaches where it was easier to introduce students to a research community. However, it was female mentors who mentioned doing this through creating layered mentoring models involving graduate students.

\subsection{Involve the right people}

Controlling the mix of staff and students, ensuring a good 'fit' between participants, optimising research group size, and 'building a sense of community among members of the research team' (Salient Practice 5) were all crucial to developing an environment in which students were free to engage.

[There] has to be a chemistry between everybody. One person that doesn't fit in the lab can mess up the whole group in no time. I observe how the undergraduate and the graduate students behave during the period that we are working on the basics. Based on that, then I make up a pairing. [H4, Female, Allied Health (Pharmacological/pharmaceutical sciences), Institutional award, US]

Linking the environment and personnel back to a balance between maintaining high expectations in a safe environment, ensures that engagement is supported in a setting where mentors can create challenge through controlling recruitment. However, it also revealed a 
tension between the need for a selection process to ensure a high quality experience, yet grounded on inclusive mentor values:

What we're looking for, for our program, isn't students who would be succeeding on their own. We don't take the absolutely best of the best. We're looking for the students who would genuinely have some sort of positive impact in their lives for them to be in this program $[\mathrm{H} 7$, Male, STEM (Computer Engineer), National award, US]

The mix of staff and students in a learning community relates to Kuh and O'Donnell's (2013) 'Interactions with faculty and peers about substantive matters' (Element 3 ) through regular activities in which peer mentoring is developed. Inviting social science students to a 'salon' discussion event about anthropological and sociological ideas, outside the curriculum, was an example of mentors creating spaces to find out which students were genuinely interested in engaging with mentored research. This quote also reflects Salient Practice 9 'Create intentional, laddered opportunities for peers and "near peers" to learn mentoring skills and to bring larger numbers of undergraduates into scholarly opportunities'.

I am really big on bringing undergraduates into the fold of the lab, or having them be a part of my broader research groups that include the graduate students, on a weekly basis. They can see what would be expected of them at the next level. My graduate students can see what you can and can't expect out of an undergraduate student that you might mentor [K5, Female, Social Sciences (Psychology), Institutional award, US]

However, many award-winning faculty promoted UR beyond their own institution, through broadening participation agendas. Creating opportunities for research projects to spin out of class and starting students off early in their undergraduate careers worked well within institutions, while encouraging students who would not always get the chance to engage, such as underrepresented students and lower performing students, were important for recruitment to research programmes internally and externally. Some faculty even mentored high school students to give them a taste of research, as well as students from other institutions through national mobility programmes. What distinguished award-winning mentors in terms of recruitment was the active recruitment of students to whom they could add the most value, focussing on motivation and potential over and above top grades (see Shanahan et al 2017).

\subsection{Make it a unique experience}

In order to make research experiences unique for each student, all mentors prioritised tailoring the project, particularly with reference to 'giving students control, freedom and voice' 
in the process; this was the most frequently mentioned theme across the data set. Interestingly the practice of giving students 'control, freedom and voice' was mentioned by more female than male award winners and most commonly in the context of STEM disciplines. For students in large classes experiencing embedded research opportunities early in their undergraduate experience, mentors had to balance control in the form of appropriate support, with the freedom to encourage learning that was both personally interesting and relevant to groups:

I'm trying to get them to take complete responsibility. To feel that it's up to them to make it succeed, and I will be as hands off as is possible for me to be, but of course, because they're first years, it's impossible to be hands off. I will be very quickly trying to get them to be the ones making the decisions, not putting words into their mouths, and trying to find an aesthetic that suits the way they want to express themselves. [H5, Female, Arts and Humanities (Architecture), National award, UK]

Engaging students with a mentor's own research project allowed faculty to 'model the research process' for students, something most frequently used in practice-based disciplines.

Everything we collect for [my] project has to be collected in a standardized way. Students can learn techniques by working on that stuff and then have more freedom once they have proven themselves via responsible practice in the lab, then we can start being more creative. I have funding both from private foundations and the NSF, but the seeds of those ideas have come from student projects that are going in [a] direction that I wouldn't necessarily consider the core of my own work. [J4, Female, STEM (Biology), National award, USA]

In contrast to Salient Practice 1 from the literature review describing 'strategic pre-planning,' award-winning mentors adopted a 'just in time' approach, responding to students' needs as they arose, rather than anticipating them in advance. Kuh and O'Donnell's (2013) sixth Element was 'Periodic, structured opportunities to reflect and integrate learning'. This practice was exemplified by integrating an individual's reflection on their progress as a learner within their situated context as a researcher. Mentors conceptualised this practice as the freedom to fail, but maintained control over the reflection process.

I say "You will make mistakes. You will need to remain motivated and recognize that as a normal process." I do have to say to them at the end of this week "what do you know how to do this week that you didn't know at the 
beginning of this week?" So forcing that process of reflection on the students, not just about the outputs in terms of experimental data, but I suppose the refinement and shaping of their knowledge throughout that process is something that's easily forgotten when they're focused on getting a result that is meaningful, when actually the most meaningful outcome is that they're going to understand the process and maybe next week they have a better view of how to trouble-shoot the process. [H9, Male, STEM (Bioscience), National award, UK]

Frequent, timely, and constructive mentor feedback (Element 5: Kuh and O'Donnell 2013) provides students with a regular progress check, allowing sustained engagement in the project. Such controlled reflection provides a transition from engagement-related practices to those focussing on achievement which are outlined next.

\section{Theme 3. Celebrating achievement}

A common practice of award-winning mentors was celebrating achievement, from smallscale informal events, to formal external conferences. Control was exercised by scaffolding the experience, preparing for research dissemination, and facilitating networking opportunities to ensure a positive experience for students. Freedom was expressed in terms of sharing ownership of the project and valuing equality as co-researchers.

\subsection{Sharing power through ownership and a sense of discovery}

Mentor practices were founded on a sense of social equality, treating students first and foremost as co-researchers. Mentors described sharing a sense of discovery and, in the process, benefitting from collaboration with their students.

It was as much an exploration for me as it was for them (...) it's just the secrets of discovery... when I am open with students about what I don't know about what I'm pursuing, the students get much more interested in that question themselves, so then we can kind of find out together. [J6, Female, Arts and Humanities (Architecture), Institutional award, US]

\subsection{Sharing research publicly}


Kuh and O'Donnell's (2013) seventh Element 'Opportunities to discover relevance of learning through real-world applications' describes authentic application of the research as an indicator of success. Likewise, Salient Practices 8 and 10 describe mentors supporting students' professional development through networking and research dissemination. For students engaged in research, professional development opportunities (such as attending and presenting at conferences), provide a controlled environment for engagement with their research in a "real world" scenario, allowing students to engage in a public demonstration of competence (Element 8; Kuh \& O’Donnell 2013) supported by a mentor:

My goal is that everyone has a research output from their position here. Either have a chance to present their work at a conference or to, in many cases, add deepness to a publication. [H6, Male, Allied Health (Physical Education), Institutional award, Canada]

I think that this is probably one of the things that differentiate me from the rest of my peers in the institution. That I look in those little experiences to see where I can get something for them... they are not expecting when they get to a lab that they are going to go and present, that you are going to take them somewhere and have my hand with them, and introduce them to people. [H4, Female, Allied Health (Pharmacological/pharmaceutical sciences), Institutional award, US]

Award-winning mentors emphasise their emotional support, guidance, and helping students to navigate these events as the key to their practice, over and above the experience itself, embodying Salient Practice 4 '(Balance rigorous expectations with) emotional support and appropriate personal interest in students'. Self-directed activities and events (inviting family members to the university), and creating departmental honours ceremonies were strategically utilized as a way to share the benefits of the research across a variety of contexts (institutional, departmental, and relative to student home life) while capitalising on the experience as a means for professional development:

I have a lot of students from minority groups - Hispanic, African-Americans. A lot of them are women, their families don't understand why they do [research]. In the undergraduate research day that we have, I tell them "invite your parents, your siblings [to] see what it is that you are doing. What you want to contribute to society. What you are doing research for." [H4, Female, Allied Health (Pharmacological/pharmaceutical sciences), Institutional award, US] 
Creating opportunities for students to disseminate research findings is practised at a range of scales from institutional events, to national participation:

It's astounding, to take students who've been working on a little question to a meeting like the society for neuroscience. It will really change their lives. [H3, Female, STEM (Neuroscience), Institutional award, USA]

and even networking internationally:

Our university is involved in a couple of networks with other universities where the students are engaged in similar research and then share the results. We worked with universities in New Zealand, the U.K. and Canada.

[K11, Female, Social Sciences (Education), National award, Australia]

The threefold description which characterises award-winning practice as 'creating challenge', 'sustaining engagement', and 'celebrating achievement', suggests a linear sequence, but in reality these are interrelated activities, each informing the other in an integrated way. High expectations are integral to the possibility of public dissemination, a sense of discovery can only be shared if mentors and mentees adopt a co-researcher ethos, and students have some autonomy in the process. Through rich descriptions of the practice of balancing control with freedom in mentoring undergraduate researchers, the values underpinning this practice can be clarified.

\section{Values underlying mentor practice}

The award-winners reported a surprisingly consistent set of value characteristics and attributes (or the 'internal goods' of Macintyre 2007), despite their varying disciplines, institutional types and world region. Mentors aimed to increase student ownership and voice through tailoring an individual research experience using mentee interests and choices. All showed an interest in the 'whole student,' beyond the research project, particularly relating to future career aspirations, although across the discipline groupings social science mentors reported this most often. For many award-winners there was an underlying commitment to broaden participation in UR (Shanahan et al. 2017) through recognition of its transformative potential and the desire to provide this opportunity to address equality issues, actively recruiting students who would benefit the most (e.g. underserved groups and those lacking top grade point averages). Developing resilience in mentees through valuing perseverance was also apparent. Commitment to research dissemination was motivated by the perceived benefits of professional development activity for the students, rather than just contributing to the wider academic project. All the award-winning mentors shared a student-centred outlook. 


\section{Discussion}

The implicit values held by award-winning mentors are evident in their descriptions of their practice, as well as the standards to achieve a high impact pedagogy through undergraduate research mentoring. Award-winning mentors are defined by their expertise in carefully balancing the control they exercise with the freedoms they wish their students to experience as undergraduate researchers. Mentors maintain this balance with each individual student, even when mentoring a research team. Holding students in a liminal state (Cook-Sather and Alter 2011) requires careful judgement, acknowledging the needs of each mentee. What appears to distinguish award-winning mentors, over and above the implementation of salient practices identified from the literature, is their tacit understanding of, and ability to respond to, each students' needs in terms of moving them into potentially uncomfortable limial space. This sets in motion an identity change from student to researcher. Award-winning mentors' practice took students to 'the edge' in a professional and developmental capacity (i.e. to the edge relative to: scientific discovery; their ability to engage with creative works; their ability to network and present to peers and colleagues; their concept of career aspirations, etc.), while at the same time, providing a personal safety net within an authentic co-researcher model.

In cross referencing our rich data set to the salient practices identified from a significant review of the literature (Shanahan et al. 2015), and to Kuh and O'Donnell's (2013) eight elements of high-impact pedagogy, we identified new meta-level mentoring practices related to maintaining a professional, yet invested and personal research experience with each mentee. These practices enabled students to grow as researchers, develop their authority and voice, be challenged to achieve through risk-taking behaviour, controlled reflection, and dialogue with their mentor. Mentor practices were characterised as a balance between freedom and control, that is, moving students repeatedly into a liminal state.

One element not explicitly mentioned in the interviews was enabling majority students and students from underrepresented minority groups to benefit from collaborating and working across their differences i.e. "Experiences with diversity" (Kuh and O'Donnell's Element 4). Research by Finley and McNair (2013) and Carpi et al. (2017) found that at most institutions in the U.S., UR and other HIPs were disproportionately available to students of privilege (i.e., with a family legacy of higher education and/or with socio-economic stability). Instead, ensuring equitable access to the benefits of UR was seen as a practice for the future (Shanahan et al 2017) despite effective leadership of diverse teams being recognised as requiring intentional mentor interventions (Galinsky et al. 2015; Marin, 2000). While targeted- 
recruitment processes and aspiration-raising through one-to-one meetings were described by the award-winning mentors, there were no accounts in the interviews of addressing diversity issues between students.

There are clear implications for practice resulting from this research. The expert mentor is someone who can: balance the needs of novice researchers so that they feel challenged, but not lacking in support; help to sustain students' active engagement in the research and include them into a research community; and finally, ensure that student research and learning is celebrated and shared with a broader audience. An essential and distinctive feature of award winning UR mentoring is developing an authentic interest in the whole student (rather than just the research project).

All ten salient practices were evidenced in the award-winning mentor interviews. We suggest they form a sound basis for ongoing training and professional development activity (e.g. see Hall et al. 2017, Walkington et al. 2018). A mentoring pedagogy for the future needs to acknowledge and adapt to changes in research-based learning in universities as well as changing student demographics. There are implications for scaling up research teams while maintaining a quality experience, where students in all groups feel supported emotionally as well as academically. Furthermore, the importance of reward and recognition for UR mentors (including graduate students), as well as support for this activity within and outside of the curriculum in administrative and resource management systems, is clearly apparent. Future awards for mentoring excellence could usefully recognise mentoring which actively addresses diversity issues between students, in addition to rewarding recruitment to UR experiences. Creating low-cost opportunities for more students to experience interdisciplinary fora to engage in reciprocal and elucidatory dialogue (Walkington, Hill, and Kneale 2017) for the growing number of students participating in higher education, may be a further way to share the learning benefits more broadly and to tackle authentic real-world problems. A particular challenge for award-winning mentors was the timeframe for undergraduate work not always being sufficient to result in publication, but there is potential for the involvement of graduate students in mentoring networks to provide a continuity which would make this more feasible.

The changing nature of both higher education and research pose significant challenges to the one-to-one model of mentored UR. Research and teaching are increasingly separated by a proliferation of short-term "teaching only" and "research only" contracts to cope with growing student numbers (Dyer et al. 2016). Solving complex global problems in an era of super-complexity (Barnett 2000) will require team-based solutions and students will need to 
communicate across disciplines. While a pedagogy of one-to-one mentoring might be an early stepping stone to prepare students for research, collaborative mentoring may benefit both faculty and students (Ketcham et al. 2018). One strategy for building the capacity of mentored research opportunities could be through partnering experienced faculty with graduate students, as well as utilising the ten salient practices as a framework for reflection on different aspects of this pedagogy (Walkington et al. 2018). The evidence from this paper suggests that mentors might maximise efficacy by 'creating challenge', 'sustaining engagement' and 'celebrating achievement' through balancing freedom and control in their mentoring practice.

\section{Acknowledgements}

We gratefully acknowledge the support of the Center for Engaged Learning Seminar on Excellence in Undergraduate Research Mentoring 2014-16, Elon University, NC, USA.

\section{Declaration of interest:}

The authors have not declared any conflict of interest.

\section{References}

Barnett, Ronald. 2000. "Supercomplexity and the Curriculum." Studies in Higher Education 25 (3): 255-65. https://doi.org/10.1080/713696156.

Bradley, Evan D., Michelle Bata, Heather M. Fitz Gibbon, Caroline J. Ketcham, Brittany A. Nicholson, and Meagen Pollock. 2017. "Structure of Mentoring in Undergraduate Research: Multi-Mentor Models." Scholarship and Practice of Undergraduate Research 1 (2): 35-42.

Brownell, Jayne E., and Lynne E. Swaner. 2010. Five High-Impact Practices: Research on Learning Outcomes, Completion, and Quality. Association of American Colleges and Universities. https://www.aacu.org/publications-research/publications/five-high-impactpractices-research-learning-outcomes-completion.

Brush, Edward, Michelle Cox, Andrew Harris, and Lee Torda. 2010. "Undergraduate Research as Faculty Development." CUR Quarterly 31 (1): 6.

Carpi, Anthony, Darcy M. Ronan, Heather M. Falconer, and Nathan H. Lents. 2017. "Cultivating Minority Scientists: Undergraduate Research Increases Self-Efficacy and 
Career Ambitions for Underrepresented Students in STEM." Journal of Research in Science Teaching 54 (2): 169-94. https://doi.org/10.1002/tea.21341.

Hensel, Nancy H, and Brent D Cejda. 2014. Tapping the Potential of All: Undergraduate Research at Community Colleges. Washington, D.C.: Council on Undergraduate Research.

Cook-Sather, Alison, and Zanny Alter. 2011. "What Is and What Can Be: How a Liminal Position Can Change Learning and Teaching in Higher Education: What Is and What Can Be." Anthropology \& Education Quarterly 42 (1): 37-53. https://doi.org/10.1111/j.15481492.2010.01109.x.

Corwin, Lisa A., Mark J. Graham, and Erin L. Dolan. 2015. "Modeling Course-Based Undergraduate Research Experiences: An Agenda for Future Research and Evaluation." CBE Life Sciences Education 14 (1): es1. https://doi.org/10.1187/cbe.14-10-0167.

Crawford, I, and Jenny Olin Shanahan. 2014. "Undergraduate Research in the Arts and Humanities: Challenges, Opportunities, and Rewards." In How to Get Started in Arts and Humanities Research with Undergraduates, edited by I Crawford, S Orel, and Jenny Olin Shanahan, 1-11. Washington, D.C.: Council for Undergraduate Research.

Dyer, Sarah, Helen Walkington, Rebecca Williams, Katherine Morton, and Stephanie Wyse. 2016. "Shifting Landscapes: From Coalface to Quick Sand? Teaching Geography, Earth and Environmental Sciences in Higher Education." Area 48 (3): 308-16. https://doi.org/10.1111/area.12261.

Finley, Ashley, and Tia McNair. 2013. Assessing Underserved Students' Engagement in High-Impact Practices. Washington, D.C.: Association of American Colleges and Universities.

Fung, Dilly. 2017. Connected Curriculum for Higher Education. UCL Press. http://www.jstor.org/stable/j.ctt1qnw8nf.

Galinsky, Adam D., Andrew R. Todd, Astrid C. Homan, Katherine W. Phillips, Evan P. Apfelbaum, Stacey J. Sasaki, Jennifer A. Richeson, Jennifer B. Olayon, and William W. Maddux. 2015. "Maximizing the Gains and Minimizing the Pains of Diversity: A Policy Perspective." Perspectives on Psychological Science 10 (6): 742-48. https://doi.org/10.1177/1745691615598513.

Guest, Greg, Kathleen M. MacQueen, and Emily, E. Namey. 2012. Applied Thematic Analysis. Thousand Oaks, CA: Sage. 
Hall, Eric E., Helen Walkington, Jenny O. Shanahan, Elizabeth Ackley, and Kearsley Stewart. 2017. "Mentor perspectives on the place of undergraduate research mentoring in academic identity and career development: an analysis of award winning mentors." Internaltional Journal for Academic Development 23 (1): 15-27.

DOI:10.1080/1360144X.2017.1412972

Healey, Mick, Alan Jenkins, and John Lea. 2014. "Developing Research-Based Curricula in College-Based Higher Education," 88.

Jenkins, Alan, and Mick Healey. 2005. Institutional strategies to link teaching and research. York: Higher Education Academy.

Johnson, Sarah Randall, and Frances King Stage. 2018. "Academic Engagement and Student Success: Do High-Impact Practices Mean Higher Graduation Rates?" The Journal of Higher Education 89 (5): 753-81. https://doi.org/10.1080/00221546.2018.1441107.

Ketcham, Caroline J., Eric E. Hall, Heather Fitz-Gibbons, and Helen Walkington. 2018. "CoMentoring in Undergraduate Research: A Faculty Development Perspective." In Excellence in Mentoring Undergraduate Research, edited by Maureen Vandermaas-Peeler, Paul C. Miller, and Jessie Moore. Washington, D.C.: Council for Undergraduate Research.

Kilgo, Cindy A., Jessica K. Ezell Sheets, and Ernest T. Pascarella. 2015. "The Link between High-Impact Practices and Student Learning: Some Longitudinal Evidence." Higher Education 69 (4): 509-25. https://doi.org/10.1007/s10734-014-9788-z.

Kuh, George D. 2008. High-Impact Educational Practices: What They Are, Who Has Access to Them, and Why They Matter. Washington, D.C.: Association of American Colleges and Universities. https://www.aacu.org/publications-research/publications/highimpact-educational-practices-what-they-are-who-has-access-0.

Kuh, George D., and K. O'Donnell. 2013. Taking HIPs to the next Level. Ensuring Quality and Taking High-Impact Practices to Scale. Washington, D.C.: Association of American Colleges and Universities.

Maclntyre, Alasdair C. 2007. After Virtue: A Study in Moral Theory. 3rd ed. Notre Dame, Ind: University of Notre Dame Press.

Marin, Patricia. 2000. "The Educational Possibility of Multi-Racial/Multi-Ethnic College Classrooms." In Does Diversity Make a Difference? Three Research Studies on Diversity in 
College Classrooms, 61-83. Washington, D.C.: American Council on Education and American Association of University Professors.

Osborn, J. M. and Kerry K. Karukstis. 2009. The benefits of undergraduate research, scholarship, and creative activity. In: M. Boyd and J. Wesemann (Eds.), Pages 41-53, Broadening Participation in Undergraduate Research: Fostering Excellence and Enhancing the Impact. Washington, DC.: Council on Undergraduate Research.

Pita, Mario, Christopher Ramirez, Nathanaelle Joacin, Sarah Prentice, and Christy Clarke. 2013. "Five effective strategies for mentoring undergraduates: Students' perspectives." CUR Quarterly 33 (3): 11-14.

Shanahan, Jenny Olin, Elizabeth Ackley-Holbrook, Eric Hall, Kearsley Stewart, and Helen Walkington. 2015. "Ten Salient Practices of Undergraduate Research Mentors: A Review of the Literature." Mentoring \& Tutoring: Partnership in Learning 23 (5): 359-76. https://doi.org/10.1080/13611267.2015.1126162.

Shanahan, Jenny Olin, Helen Walkington, Elizabeth Ackley, Eric E. Hall, and Kearsley A. Stewart. 2017. "Award-Winning Mentors See Democratization as the Future of Undergraduate Research." CUR Quarterly 37 (4): 4-11. https://doi.org/doi: 10.18833/curq/37/4/14.

Shellito, Cindy, Kalyn Shea, Gary Weissmann, Anke Mueller-Solger, and William Davis. 2001. "Successful Mentoring of Undergraduate Researchers: Tips for Creating Positive Student Research Experiences." Journal of College Science Teaching 30 (7): 460-64.

Shore, Cecilia. 2005. "Toward Recognizing High-Quality Faculty Mentoring of Undergraduate Scholars." Journal of Excellence in College Teaching 16 (2): 111-36.

Tatlow, Pam. 2015. "Participation of BME students in UK Higher Education." In Aiming Higher: Race, Inequality and Diversity in the Academy, edited by Claire Alexander and Jason Arday. London: Runnymede.

Thiry, Heather, and Sandra L. Laursen. 2011. "The Role of Student-Advisor Interactions in Apprenticing Undergraduate Researchers into a Scientific Community of Practice." Journal of Science Education and Technology 20 (6): 771-84. https://doi.org/10.1007/s10956-0109271-2.

Walkington, Helen, Jennifer Hill, and Pauline E. Kneale. 2017. "Reciprocal Elucidation: A Student-Led Pedagogy in Multidisciplinary Undergraduate Research Conferences." Higher 
Education Research \& Development 36 (2): 416-29.

https://doi.org/10.1080/07294360.2016.1208155.

Helen Walkington, Eric E. Hall, Jenny O. Shanahan, Elizabeth Ackley, and Kearsley Stewart. (2018). Striving for excellence in undergraduate research mentoring: The challenges and approaches to ten salient practices. In Vandermaas Peeler - M., Miller, P., Moore, J. (Eds.) Excellence in Mentoring Undergraduate Research. Washington D.C.: Council on Undergraduate Research.

Winch, Peter. 1990. The Idea of Social Science and Its Relation to Philosophy. 2nd ed. London: Routledge. 


\section{Supplementary materials}

\section{Interview Protocol}

- What got you interested in mentoring undergraduate research specifically?

- Could you give me a sense of the types of undergraduate research mentoring that you do?

- How would you describe your relationship with your mentees?

- What do you think makes your mentoring practice effective?

- Can you tell me about a time when your mentoring worked particularly well?

- What challenges have you experienced in your role as an undergraduate research mentor?

- How has your mentoring practice changed over time?

- How does undergraduate research mentoring fit into your career?

- Do you think the practice of undergraduate research mentoring is going to change in the next 5 to 10 years? If yes, how?

- Is there anything else you'd like to say about effective mentoring practices in undergraduate research? 
Table 1: Ten salient practices of undergraduate research mentors identified from a literature review (Shanahan et al 2015; Walkington et al 2018)

Practice 1: Pre-plan strategically to respond to students' varying needs and abilities throughout the research process.

Practice 2: Set clear, scaffolded expectations.

Practice 3: Teach the technical skills, methods, and techniques of conducting research in the discipline.

Practice 4: Balance rigorous expectations with emotional support and appropriate personal interest in students.

Practice 5: Build a sense of community among members of the research team.

Practice 6: Dedicate time to one-on-one, hands-on mentoring.

Practice 7: Increase student ownership of the research over time.

Practice 8: Support students' professional development through networking and explaining norms of the discipline.

Practice 9: Create intentional, laddered opportunities for peers and "near peers" to learn mentoring skills and to bring larger numbers of undergraduates into scholarly opportunities.

Practice 10: Encourage and guide students to share findings in presentations and writing. 
Table 2: Characteristics of the 32 Award-winning participants

\begin{tabular}{|c|c|}
\hline Characteristic & Distribution \\
\hline Award Type & $\begin{array}{l}\text { National = } 12(37.5 \%) \\
\text { Institutional = } 20(62.5 \%)\end{array}$ \\
\hline Country & $\begin{array}{l}\text { United States }=25(78.1 \%) \\
\text { United Kingdom }=4(12.5 \%) \\
\text { Australia }=2(6.3 \%) \\
\text { Canada }=1(3.1 \%)\end{array}$ \\
\hline Discipline & $\begin{array}{l}\text { Arts and Humanities = } 7(21.9 \%) \\
\text { Social Sciences }=14(43.8 \%) \\
\text { STEM }=8(25.0 \%) \\
\text { Allied Health }=3(9.4 \%)\end{array}$ \\
\hline Rank & $\begin{array}{l}\text { Assistant Professor }=3(9.4 \%) \\
\text { Associate Professor }=18(56.3 \%) \\
\text { Professor }=11(34.4 \%)\end{array}$ \\
\hline Institution Classification & $\begin{array}{l}\text { Undergraduate }=6(18.8 \%) \\
\text { Master's Comprehensive }=7(21.9 \%) \\
\text { Doctoral Granting }=19(59.4 \%)\end{array}$ \\
\hline Institution size & $\begin{array}{l}>15,000 \text { students }=21(65.5 \%) \\
5,000-15,000=7(21.9 \%) \\
<5,000=4(12.5 \%)\end{array}$ \\
\hline Gender & $\begin{array}{l}\text { Male }=14(43.8 \%) \\
\text { Female }=18(56.3 \%)\end{array}$ \\
\hline Years of Mentoring & $16.2 \pm 10.6$ years \\
\hline
\end{tabular}


Table 3: Table showing the spread of disciplinary areas covered by the Awardwinning mentors (32 participants) interviewed.

\begin{tabular}{|l|l|}
\hline Arts and Humanities (7) & English (3) \\
& Architecture (2) \\
& French (1) \\
& Theatre (1) \\
\hline Social Sciences (14) & Psychology (4) \\
& Economics (2) \\
& Education (2) \\
& Law (1) \\
& Integrated Studies (1) \\
Conflict Analysis (1) \\
& Political Science (1) \\
& Sociology/Anthropology (1) \\
& Urban Planning (1) \\
\hline STEM (8) & Computer Science (3) \\
& Biology/Bioscience (2) \\
& Neuroscience (1) \\
& Physics/Astronomy (1) \\
\hline Allied Health (3) & Medicine (1) \\
& Physical Education (1) \\
& Pharmaceutical Sciences (1) \\
\hline
\end{tabular}

